\title{
Art Therapy for Elderly Women Diagnosed with Alzheimers: A Positive Person-Centred Approach Increases Ease in the Care Process
}

\author{
François Deygout*1 and Guy Auburtin ${ }^{2}$ \\ ${ }^{1}$ Art therapist, Faculty of Medicine, France \\ ${ }^{2}$ Former Head Doctor of the Department of Preventive Medicine of the City of Paris, France \\ *Corresponding author: François Deygout, Art therapist, Faculty of Medicine, France
}

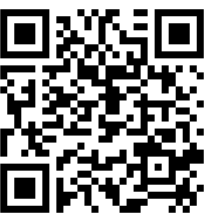

\section{ARTICLE INFO}

Received: 慧 October 15, 2019

Published: 慧 October 23, 2019

\section{ABSTRACT}

Keywords: Alzheimer's Elderly Women; Anxiety; Art Therapy; Person-Centred Approach; Trust

Citation: François Deygout, Guy Auburtin. Art Therapy for Elderly Women Diagnosed with Alzheimers: A Positive Person-Centred Approach Increases Ease in the Care Process. Biomed J Sci \& Tech Res 22(2)-2019. BJSTR. MS.ID.003727.

\section{Introduction}

\section{Background}

"Art and art therapy is regarded as a haven, getting a clearer view, clearing the way emotionally and enhancing and enlivening the self." These narratives resulting from experienced storylines from Collie et al. [1] realistically sum up the clinical benefits experienced by people in pain when they become involved in art. Such storylines also show existence being affirmed, better wellbeing achieved through artistic expression and "meaning making being achieved through physical acts of making" Collie et al. [1]. This is really a therapeutic purpose of art therapy. Art via arttherapeutic processes can give to people an empowering healing process that makes meaning making easier and positive arts interventions promote psychological well-being Darewych et al. [2]. Art and aesthetics, by stimulating creativity and embodiment, also re-educate people and facilitate social connections Byers et al. [3-8]. In France, increasing numbers of suffering persons have used a non-pharmacological supportive aesthetic-based activity in healthcare called modern art therapy. Modern art therapy refers to beauty. It has been defined by its founder Richard Forestier as "the exploitation of the artistic potential of an individual in a humane and therapeutic goal" Forestier [9]. This therapy also defines art as "a humane and voluntary action, aesthetics oriented" and emphasizes the physical engagement in the art making as a key factor through the therapeutic process to recover self-esteem. It is then regarded as a sensory stimulation intervention Lusebrink [10] to help patients participate in the therapeutic process by an increase in feeling pleasurable and aesthetic sensations Forestier et al. $[9,11]$. This art-based therapy also relies on the preserved abilities of the individuals, rather than attempting to correct the disabled part.

Evidence has suggested that aesthetic preferences and stimuli remain constant for people diagnosed with neurodegenerative diseases such as Alzheimer's Byers et al. [3-5,12-15]. Human beings, in spite of incredibly debilitating diseases, do not stop creating art. People with neurological diseases continue to express themselves through art Miller [7] and to manage aesthetics Byers [3] as the degenerative illness progresses. Aesthetic experience lies in the articulation of unconscious processes Byers [3]. Neurodegenerative diseases provoke stress and distress, and a multisensory stimulation such as art therapy has a significant effect on the resulting anxiety 
and quality of life Baker et al. [4,16-20]. In this way, the purpose of aesthetics-based art therapy sessions for such affected people is to steer the person through her/his self-realization, creating pleasurable sensations, feelings of beautifulness and ultimately recovering her/his self-esteem.

As such, people diagnosed with neurodegenerative diseases improve their self-esteem and well-being by using creative activities by means of acts of making, which produce pleasure and reduce anxiety Byers et al. [3,5,21-25]. This is likely because neurodegenerative diseases have an impact on the human memory and decrease cognitive faculties, but emotions and affect are less impacted by degeneration Baran et al. [26-31]. Fundamental properties of artistic technique can then be used to help people participate in the therapeutic process, and people affected by such diseases remain sensitive to subjective art-based experiences Camic et al. [5,32-36]. Systematic reviews have also suggested that creative art therapy is effective for the treatment of behavioural and emotional challenges resulting from the diseases Cowl et al $[4,37,38]$, and an emotional enhancement of memory effect has been seen in people with neurodegenerative diseases Baran et al. $[26,39,40]$. It also appears that positive emotions broaden the scope of action and build physical resources Fredrickson [41]. In addition, non-pharmacological interventions have the potential to improve psychological aspects such as cognitive improvement via neuroplasticity Ehresman et al. [4,42,43].

To date, art-therapy-oriented studies that have focused on the self-esteem of affected persons have shown an increase in global self-worth Chancellor et al. [1,23,25,44-47]. Trust and confidence being part of self-esteem, art therapy is helpful in building greater trust and self-disclosure Hartz et al. [47] and creative processes are identified in its acts to inherently give people the authority or power to do something promoting empowerment and selfassertion Franklin [46]. Cognitive behavioural therapies show that the patient is not the only factor involved in the therapeutic process. The therapists, as well as the relationship, are regarded as key determinants (more specifically, the therapist's attitudes and behaviours) Lambert [48]; Lambert, Okiishi et al. [49-51]. In a systematic review of the clinical effectiveness of art therapy among people with non-psychotic mental health disorders, the patienttherapist relationship appears to be an important determinant in successful treatment Uttley et al. [52]. Also, some studies precisely demonstrate that art therapy's effectiveness is mainly therapistbased with regard to the used approach Cavazos [53], and the therapist's variability in the alliance is seen to be more important than the patient's variability for improved patient outcomes Del Re et al. [54]. Also, in psychotherapy, the accounted variance of the therapist is seen to be eight times more than the variance of the patient in treatment Lambert [48].

Overall, quantified common factors, which include the patienttherapist relationship, account for $30 \%$ of the variance in patient outcomes Lambert et al. [55]. In particular, personal attributes of the therapist, such as confidence and trust within the therapeutic frame, are regarded as essential to the therapeutic success Ackerman et al. [56] and some studies show that a built and reliable physician-patient working alliance requires affective dimensions such as trust Fuertes et al. [57-60]. In addition, trust in physicians has been shown to be improved by using a patient-centred approach Berrios-Rivera et al. [61], and the alliance is similarly found to strongly correlate with patient centeredness Huff et al. [59]. This is because the therapeutic bond comes first through building mutual trust Berdondini et al. [27,62]. In the same way, an authentic partnership approach including trust is more and more required in dementia care Dupuis et al. [63]. People with neurodegenerative disease maintain an affective memory, which allows them to know what attitude to adopt, depending on the people present PoncetJeanne [64]. Consequently, it can be expected that trusting the therapist will allow a decrease in the anxiety of the patient, who is reassured and who thus acquires a certain emotional availability.

Thus, the quality of the relationship that the carer will establish with the patient will be a central element in the care of these people Poncet Jeanne [64]. This is particularly true when the session occurs in a non-judgmental atmosphere Collie [65,58]. Nonjudgmental absorption in what is being observed by the therapist requires empathy that enhances the therapeutic alliance Ackerman et al. $[56,66,58]$. Regularly, studies have demonstrated that patientperceived empathy has increased patient trust Bachelor et al. [67$69,58,70,71]$ and active participation Raglio et al. [72,25]. A study conducted in the UK by Evans-Jones et al. particularly underlined the importance of empathy for cognitive-behavioural therapies Evans-Jones et al. [73]. Empathy has also been noted to lower patients' anxiety and distress Derksen et al. [69]. An empathic behaviour is part of a person-centred approach. Established by Carl Rogers in 1961 [74], this type of approach diverges from the traditional model of the therapist as expert and moves instead toward a non-directive, empathic approach that empowers and motivates the client in the therapeutic process Rogers [74]. A goal of a person-centred approach is to assist patients in becoming more autonomous and confident. In this context, the purpose of the therapist is to create a growth-promoting atmosphere to solve problems by being an empathic and attuned therapist Cavazos et al. $[53,75]$. Such approach is seen as effective for people with dementia Clisset et al. [76-79].

\section{Objectives and Hypothesis}

This case study aimed to address the influence of the empathic therapist's behaviour in developing interpersonal trust through the therapeutic alliance during modern art therapeutic-based sessions. Clinical observations regarding the use of a person-centred approach were supposed to demonstrate that trust is essential in order for the patient to develop self-confidence and then commit to the activity. In particular, trust is expected to be the initial lever acting at the beginning of the relationship, and therefore in all the therapeutic process. 


\section{Research Model}

Self-confidence has already been regarded by some researchers as suitable for expressing self-esteem and personal autonomy. To accurately define self-esteem, Bernhard et al. [80] specifically established a tripartite model based on the sum of three pertinent components, namely, love of self, self-confidence and assertiveness. As a patient's trust is an additional level that can be used by the therapist's behaviour to emphasis confidence, it was added in Bernhard et al. [80] model to define a new one, expressed as follows:

$[$ self-esteem $]=[$ love of self $]+[$ trust $]+[$ self-confidence $]+$ [assertiveness]

Consequently, a research model was stated as such:

1. The therapist establishes a confidence-based relationship by developing a patient's trust, which is initiated and reinforced with the help of an empathic person-centred approach.

2. Trust connects the patient with the therapist and with her/himself. This mirrored confidence reactivates his/her selfconfidence.

3. Self-confidence makes the patient want to commit to the activity.

\section{Methodology}

\section{Purpose of the Study}

Modern art therapy identifies two main behaviours: a contemplative mode when the patient observes the therapist acting and an active mode when the patient actively participates in drawing and/or painting. In both modes, an aesthetic intention is present: both modes initiate a reinforcement loop linked to the contemplation and the desire of mimesis Forestier [9]. Modern art therapy emphasizes the physical engagement in the art making as a key factor through the therapeutic process to recover self-esteem. Thus, the intention of the art-therapist is to initiate or facilitate the action during the session because the final objective is to decrease anxiety via making and feeling. However, modern art-therapy does not recommend any positive approach based on empathy such as the one developed by C Rogers [81]. It primarily focuses on the care effect of art on self-esteem, aesthetics-wise. The purpose of this study is to show how a positive (Roger's) approach can facilitate this process by first establishing client trust that facilitates engagement in aesthetic activities. The reinforced empathic behaviour, part of a person-centred approach is used in this way. In addition, the arttherapist can ask the patient to express the pleasure that results from the artistic activity and that contributes to the increase of selfesteem Forestier [9].

\section{Participant Inclusion/Exclusion Criteria}

A partnership was established with a University Hospital in Burgundy, France, which manages a nursing home unit specifically dedicated to severe-stage Alzheimer's patients. This long-term geriatric area can receive 39 residents who are in the later stages of dementia, divided into three 13-bedded secured care units. The population was predominantly female (just one man). The sexual gender was consequently the first factor of inclusion. The geometric mean of the age of the women was 86 years, with a variation from 69 to 98 years. The average duration of institutionalization was found to be 23 months, with a variation ranging from 1 to 70 . The measured Mini Mental State Examination tests (MMSE's), Folstein [82] ranged from 1 to 15 . Nine women were excluded because of temporary absence from the units, hospitalization (deteriorated health status) or not being able to attend a session (continuous ambulation). From the twenty-nine listed women left, twelve participants were randomly assigned. The draw identified five residents for the first unit, three residents for the second one and four for the last one.

\section{Ethical Approval}

Ethical approval prior to the implementation of the study was obtained from the carers, mainly the families. The signed forms were stored in the files of the patients and were available on request.

\section{Settings, Protocol and Therapeutic Strategy}

The duration of the study was set for four months. Weekly sessions were planned. One-to-one contact was preferred. An important aspect of the therapy was to provide a safe environment in order to encourage the patient to commit, especially for people with high levels of anxiety Turnbull et al. [83]. Consequently, individual art therapy sessions were planned for each participant and conducted by the corresponding author of this study graduated in modern art therapy. Note that when a participant refused to enter the room at the last minute or to sit down at the desk, or went back, the session was not recorded. The first session was regarded as an opening session and resulted in a discussion. It was also an attempt to complete the anamnesis often partially described in the medical file. The therapeutic strategy was first mimesis oriented during the starting sessions in order to connect any aesthetic intention. After asking the patient "What would you me to draw for your pleasure, what could I draw that could make you happy?", the art-therapist started to draw or paint and engaged the discussion in the same time to build interpersonal trust. A special focus was put on the emotional enhancement of memory by using souvenirs linked to family members or great personal details of their past life. The patients were also verbally and progressively led to develop their visual creativity by soliciting their imagination with the help of personal details of their lives and the use of preferred colours as preferences, because colours were observed as stable, despite the disease Miller et al. [7,84] and were preferably seen to contribute to the sensual aspects of art-making amongst older women Reynolds.

\section{Methods of Analysis}

An observational grid was adequately established to fit with the modified Bernhard et al. [80] model. Nine items were identified per 
component (36 items in total). Behavioural items were preferred. The Appendix 1 describes the resulting grid and the Appendix 2 the glossary that defines each item which, was independently quantified using a 5-point Likert scale ranging from 1 to 5 . The scores were quoted by the therapist from his field observations just after the session. Note that when an item was not observed during the session, it was not rated (previous calculations showed that an added default score set at " 3 " to complete the matrix can significantly reduce the experimental variability). Such raw quoted data were used for the variability study and data were averaged per component and per session to calculate and monitor the self-esteem progression (Figure 1).

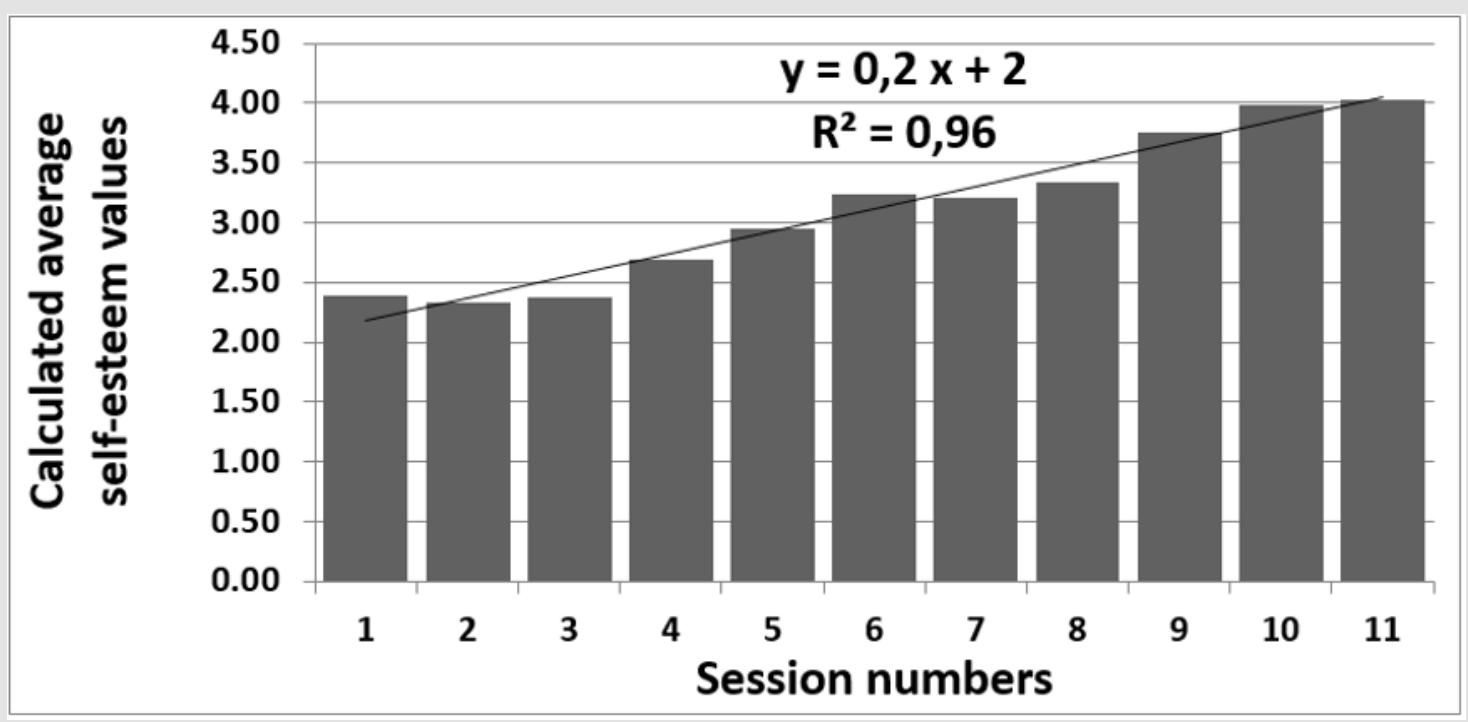

Figure 1: Overall tendency of the self-esteem progression for the whole population.

\section{Statistical Analysis}

All statistics were calculated with a 95\% confidence level in probability (Minitab PC 16 version). A p-value above 0.05 was regarded as not significant. No shift over time of the data was observed (time series analysis). The random distribution of the residuals was also checked for each calculation (homoscedasticity). The impact of some interesting field variables was studied: the within person variability (first name), her age, her MMSE value, the duration of institutionalization, the living unit, the moment of the activity (morning versus afternoon), the number of sessions and the mode (active, i.e., physical versus contemplative mode). Some variables were considered as having a weak influence over the duration of the study: the daily therapeutic treatment (regular during the survey for each resident and based on several molecules), the type of carers (nursing or family) and the anecdotal contribution of the psychologist when required. On the other hand, the past practice of an artistic activity was ignored because of a partial anamnesis and the significant loss of cognitive abilities. A Shapiro-Wilk test showed a normal distribution for the quoted items ( $\mathrm{n}=3289$ ) during the sessions for the 12 people when the item was quoted (see the appendix 1, 36 items per person and per session). Consequently, parametric statistics were used with no transformation. Multivariate General Linear Model ANOVA and correlation/regression tools were used. A minimum limit of 0.15 was established for the Pearson coefficient to consider the variables and 0.25 to quantify its response ( $\mathrm{R}^{2}$ regression value). The 36 -item grid had a satisfactory degree of internal consistency. Cronbach's $\alpha$ was found to be 0.65 , taking into account the four components of self-esteem ( $n=579)$ and 0.70 without assertiveness ( $n=646)$, assertiveness having the lowest number of calculated correlations.

\section{Results}

Except for one woman who remained in the contemplative mode, all patients became active during the course of the sessions. Between four and eight sessions (five on average) were required for a patient to become active. The bodily commitment was remarkable and observable via a positive gap of the quoted items. The clinical variability of the main field variables on self-esteem was studied via ANOVA ( $\mathrm{n}=3289$ ). The mode was coded as a dichotomous variable $(\mathrm{Y} / \mathrm{N})$. Table 1 summarizes the results. Overall, the expressed variability is slightly above $100 \%$ (106\%), which means there was a residual collinearity between the chosen variables. The two most influential identified factors were the mode type and the number of sessions. As previously described, action is key (F-value of 996). The living unit factor had a weak but noticeable impact, as it was the third pertinent factor (F-value of 81). This influence was confirmed by the staff in particular for one unit, in which the most dependent patients were preferably placed. Patient-related variables were seen to have a similar influence. The time of the session (morning versus afternoon) had no influence, which could facilitate the organization. 
Table 1: Expressed variability of the influence of the main clinical variables.

\begin{tabular}{|c|c|c|c|}
\hline Clinical Variables & $\begin{array}{c}\text { Expressed } \\
\text { Variability }\end{array}$ & F-Statistic & p-value \\
\hline $\begin{array}{c}\text { Mode (contemplative vs } \\
\text { active) }\end{array}$ & $23 \%$ & 996 & $<0.001$ \\
\hline $\begin{array}{c}\text { Number of sessions } \\
\text { The person herself (first } \\
\text { name) }\end{array}$ & $22 \%$ & 91 & $<0.001$ \\
\hline Age of the person & $15 \%$ & 54 & $<0.001$ \\
\hline $\begin{array}{c}\text { Duration of } \\
\text { institutionalization }\end{array}$ & $15 \%$ & 58 & $<0.001$ \\
\hline MMSE of the person & $11 \%$ & 50 & $<0.001$ \\
\hline Living unit & $5 \%$ & 81 & $<0.001$ \\
\hline $\begin{array}{c}\text { Morning vs afternoon } \\
\text { (session) }\end{array}$ & $<2 \%$ & 10 & $<0.001$ \\
\hline
\end{tabular}

Regarding the personal features of the person (age, duration of institutionalization and MMSE value), only the MMSE was found to slightly correlate with self-esteem $(r=0.25, p<0.001)$. In the same way, a significant correlation was determined between MMSE and the age of the person $(\mathrm{r}=0.51, \mathrm{p}<0.001)$. The experimental variability of the physical activity (making), which occurred when switching from the contemplative to the active mode was expressed with regard to the components of self-esteem. The idea was to bond self-esteem and the action, which is the core of the care in modern art therapy. The results are summed up in Table 2 ( $n=578$ out of 963 due to incomplete data). $96 \%$ of variability was explained by the model. Trust was expressed as the most influential component on the intention to act (F-value). Consequently, the first part of the research model was verified: patient trust is first required and is facilitated by a person-centred approach set up by the therapist. With the help of rounded values of the calculated variability in Table 2 , self-esteem was represented by the following equation (eq. 1):

[self-esteem $]=0.2$ [love of self] +0.4 [trust $]+0.2$ [selfconfidence] +0.2 [assertiveness] (eq. 1)
Table 2: Influence of the components of self-esteem on the making..

\begin{tabular}{|c|c|c|c|}
\hline Components of Self-Esteem & $\begin{array}{c}\text { Calculated } \\
\text { Variability }\end{array}$ & F-Statistic & p-value \\
\hline Love of self & $17 \%$ & 111 & $<0.001$ \\
\hline Trust & $37 \%$ & 330 & $<0.001$ \\
\hline Self-confidence & $21 \%$ & 156 & $<0.001$ \\
\hline Assertiveness & $21 \%$ & 153 & $<0.001$ \\
\hline
\end{tabular}

By the help of this equation, self-esteem was calculated from the Likert scale data and an overall tendency of self-esteem was depicted for the whole population (Figure 1). A coefficient of 0.96 was determined, meaning a robust first-order regression. The equation $(y=0.2 x+2)$ showed that theinitial self-esteem mean value doubled at the end of the four-month follow-up. The coefficient of proportionality of 0.20 expressed an overall gain of one point every five sessions. According to this model, correlations were calculated between the components of self-esteem (time analysis). Overall, correlations increased with time (Table 3). The first significant correlation that manifested from Session 3 was love of self versus trust $(r=0.18, p=0.012)$, followed by trust versus self-confidence from Session $4(r=0.16, p=0.006)$. Again, trust was regarded as the first lever, acting whatever the mode was. The correlations progressively reinforced over the course of the sessions, following the order of the model. The correlations involving trust and selfconfidence were found to be significantly stronger in the active mode (e.g., see the cases from Session 6). This verified parts 2 and 3 of the research model: trust reactivated self-confidence, which manages the physical engagement. From Session 8, the correlation between self-confidence and assertiveness became positive for active people only $(\mathrm{r}=0.27, \mathrm{p}<0.001)$. Overall, there were no observed positive correlations related to assertiveness when there was no action, since assertiveness requires self-assessed productions.

Table 3: Calculated correlations illustrating the connections over time between the self-esteem components.

\begin{tabular}{|c|c|c|c|c|}
\hline \multicolumn{2}{|c|}{} & \multicolumn{3}{c|}{$\begin{array}{c}\text { Pearson Coefficients (and p-values) } \\
\text { Obtained between }\end{array}$} \\
\hline Number of Sessions & $\mathbf{n}$ & Love of Self and Trust & Trust and Self-Confidence & Self-Confidence and Assertiveness \\
\hline \multicolumn{7}{|c|}{} & \multicolumn{5}{|c|}{ Whole Population (12 Patients) } & $0.01(0.78)$ \\
\hline 3 & 324 & $0.18(0.012)$ & $0.02(0.72)$ & $-0.01(0.91)$ \\
\hline 5 & 432 & $0.27(<0.001)$ & $0.16(0.006)$ & $-0.01(0.87)$ \\
\hline 6 & 540 & $0.30(<0.001)$ & $0.21(<0.001)$ & $0.06(0.23)$ \\
\hline 8 & 648 & $0.37(<0.001)$ & $0.36(<0.001)$ & $0.11(0.060)$ \\
\hline 11 & 810 & $0.40(<0.001)$ & $0.45(<0.001)$ & $0.20(<0.001)$ \\
\hline 6 & 963 & $0.44(<0.001)$ & $0.16(0.05)$ & $-0.24(0.004)$ \\
\hline 8 & & Population in Contemplative Mode (4 Patients) & $-0.25(0.001)$ \\
\hline
\end{tabular}




\begin{tabular}{|c|c|c|c|c|}
\hline 6 & 432 & $0.36(<0.001)$ & $0.32(<0.001)$ & $0.18(0.01)$ \\
\hline 8 & 540 & $0.40(<0.001)$ & $0.40(<0.001)$ & $0.27(<0.001)$ \\
\hline \multicolumn{5}{|c|}{ Population in Active Mode (11 Patients) } \\
\hline 11 & 918 & $0.44(<0.001)$ & $0.46(<0.001)$ & $0.21(<0.001)$ \\
\hline
\end{tabular}

Expected levels of the individual components of self-esteem that could be regarded as satisfactory were predicted with regard to trust, which was regarded as a marker of the person-centred approach set up by the therapist. Based on the four components, linear regressions were first calculated using data only collected during the active mode. Interestingly, when trust was considered in a calculation, the three other components became non-relevant and were excluded. The continuous field variables were also computerized; only MMSE and the number of sessions appeared to be influent (see equations 2 to 4; $\mathrm{n}=675,744$ and 697 respectively):

Love of self $=2.1+0.18$ Trust +0.09 [number of sessions] +0.02 MMSE (eq. 2)

Self-confidence $=2.1+0.15$ Trust +0.07 [number of sessions $]+$ 0.03 MMSE (eq. 3)

Table 4: Influence of a person-centred approach on the number of sessions for given values of the components of self-esteem.

\begin{tabular}{|c|c|c|c|c|}
\hline Number of Sessions Required to Obtain & $\begin{array}{l}\text { Non-Person-Centred Approach } \\
\text { (Trust Factor }=0 \text { ) }\end{array}$ & $\begin{array}{l}\text { Person-Centred Approach } \\
\text { (Trust Factor = 5) }\end{array}$ & p-value & \\
\hline (from Equations 2 to 4 ) & MMSE = 1 & MMSE = 15 & MMSE = 1 & $\mathrm{MMSE}=15$ \\
\hline Love of self $=4$ & 21 & 17 & 11 & 7 \\
\hline Self-confidence $=4$ & 26 & 21 & 16 & 10 \\
\hline Assertiveness $=4$ & 11 & 6 & 16 & 11 \\
\hline
\end{tabular}

\section{Discussion}

\section{Empathy}

The present results reinforced previous outcomes regarding the impact of trust in the therapeutic relationship, which can be facilitated by a patient-centred approach Rogers [74]. The tripartite model presented in this study could be compared with what Rogers called "the dynamics of change" when he referred to his approach Rogers [74]; pp 63-64:

a. In the present study, patient trust was first initiated and reinforced in an empathic person-centred approach (part 1 of the present research model). For Rogers, as the patient found someone else listening acceptantly to his feelings, he little by little became able to listen to himself and more acceptant of himself.

b. The felt trust connected the person with him/herself, and this mirrored confidence reactivated his/her self-confidence (part 2 of the model). Rogers declared that as the patient found the therapist showing a consistent and unconditional positive regard for him and his feelings, slowly he moved towards taking the same attitude towards himself and was therefore ready to move forward in "the process of becoming".
Assertiveness $=2.7-0.14$ Trust +0.12 [number of sessions] + 0.04 MMSE (eq. 4)

The factor quantifying trust was found negative for assertiveness. The number of sessions required for a patient to reach satisfactory values mirroring the field results for each component was calculated (the value was set up at 4) either with a person-centred approach (using the maximum value for a patient's trust, i.e., 5) or without (no established patient's trust, i.e., 0). Table 4 summarizes the results obtained within the encountered MMSE value range (quoted from 1 to 15 by the physicians of the units). A helpful person-centred approach significantly reduces the number of sessions for a targeted level of self-esteem. On the other hand, such an approach adversely impacts assertiveness during the course of the sessions. The MMSE impact is similar whatever the approach is (a gap of five sessions). c. Self-confidence made the patient active (part 3 of the model). Rogers concluded that as the patient finally listened more accurately to the feelings within, he also moved toward greater congruence. He found it possible to move out from behind the façades he had used. He found that he was at last free to change and to grow.

The present study also shows that Rogers' dynamics of change theory can be applied for people with neurodegenerative diseases having support with art-therapeutic activities. Similarly, psychotherapists have found that developing real trust is often achieved via repeated testing of the relationship Morstyn [85]. In such an embodied relationship, subjective feelings and associations are directly intuited between patient and therapist while sitting together in a room. Such an approach is recommended for disoriented patients, which enables direct observations such as judged emotions Lawton [86,87-97]. This approach has also been successfully used to take care of patients with depressive symptoms Bickmore et al. [98]. The important point is that the feelings of trust, genuineness, and empathy are all lived experiences and that they derive their entire meaning from their individual embodied, spatial and temporal context Morstyn [85]. With an empathic approach, the therapist can tune his/her answer regarding the patient faculties 
and capacities. For Rogers, the concept of trust focuses more on trusting the potential within the individual even before it manifests in his/her outward behavior Rogers [81].

Rogers defined facilitative attitudes, which are congruence, empathy, level of regard and unconditional regard, and the more the therapist will develop these attitudes, the more the patient will trust the therapist (Rogers, 1961). For this study, the empathic approach is expressed by frequent eye gaze, listening and attentiveness to the talk of the patient, and sometimes humour. In order to foster trust, non-verbal behaviour, active listening and paraphrasing is also used Fuertes et al. [74]. However, therapist ratings of trust and facilitative attitudes do not always show the expected correlations with patient ratings of the same elements in long-term relationships because the model of trust may be assessed more accurately in the early stages of therapy, when patients' trust in their therapist develops Peschken et al. [89]. The present results confirm that there is a development stage for trust. After this stage, the results also show that the approach adversely impacts assertiveness over time. This is likely because assertiveness means more autonomy on behalf of the patient and therefore less empathy from the therapist. When the patient begins to show or express his/ her assertiveness, the therapist must modify their person-centred approach. In the present case, the therapist must pay attention to their behavior at least from Session 6, especially for the patients having the highest MMSE values (Table 4).

\section{Five Sessions to Commit}

At the beginning of the relationship, the bond can be regarded as fragile and it develops through a series of passages - first through building trust, which occurs only when the patient realizes that the therapist is on her/his side (no need for supervision) and she/he can accept what interesting experience can come out of it Quattrini [90]. The patient at this time can usually accept what the therapist suggests, even if the suggestion is not necessarily appealing at first. There were opportunities during this survey for the therapist to signal his desire to take care of the patient during the contemplative stage. A significantly higher level of trust can be observed in the relationship to respond when the other person takes the initiative to signal his/her desire to be trusted Swinth [91]. Thus, with the therapeutic bond elaboration coming first in trust/safety conditions, the patient is able to take her/his eyes off the therapist and think about her/his well-being Berdondini et al. [27]. A productive collaboration is not necessarily a natural or spontaneous process. It requires a series of efforts for both patient and therapist, meaning several sessions Berdondini et al. [27]. In average, five sessions are required here to build a sufficient and identifiable trust-based relationship. Then, the contemplative period of time can be regarded as a "builder of trust".

During a previous follow-up involving mild cognitive impairment people receiving in-home care, between four and five sessions were required for these patients to operate Deygout
[92]. This number of five sessions follows certain reproducibility. Some authors have described the first critical alliance phase as being the initial development, which usually takes place within the first five sessions. During this phase, trust must be established Horvath et al. [93]. Also, in a non-directive teaching experience with students, Rogers set unstructured courses without informing the class about it, just answering questions and waiting for student initiatives Rogers [74], pp 299-304. By the fifth session, something definite had happened. Students spoke to one another and the selfconscious group became an interacting group, a brand new cohesive unit, carrying on in a unique way. It took the class four sessions to realize that they were wrong and that they were very likely to develop mutual trust and self-confidence. Interestingly, Rogers also reported the case study of Mrs. Oak in a storyline regarding the experiencing of the potential self. From an early part of the fifth interview, verbal material emerged that described her awareness of experience, which was previously discussed Rogers [74], p 77.

\section{Absence of Judgment and Congruence}

Rogers recommended an "unconditional positive regard" through his facilitative attitudes, meaning a kind of non-judgmental and congruent attitude. With art therapy, the patients can have an absolute trust in what their artistic activities can reveal to them. Implicit trust in art can be central to the narratives told by patients, especially images Collie et al. [1]. Art products, as well as the art making process, are a vehicle for healing and the therapy is transacted in relation to the art products that the patient makes as well as in relation to the therapist Collie [65]. From Collie's work, two items emerged through collected narratives: the (safety) atmosphere of non-judgment created by the art therapist and the sense of trust that could develop as a result. The absence of even the slightest trace of judgment lets the patient's trust and his/ her trust in the process develop. Immigrant students performing art therapy-based activities had a similar feeling. They remarked that when they earned respect from their peers, they were more likely to obtain self-esteem; they suggested that self-esteem firmly depends on the way peers see you Chen [45]. Thus, another way to see the present research model would be to consider the empathic behaviour of the therapist as a mirror that reflects the patient's trust and transforms it into self-confidence: "The therapist directs the looking; without the therapist, you might stick with what you were already thinking and a lot more can came out with the therapist's direction" Collie [65]; Patricia's narratives p 136.

\section{Aesthetics and Affect}

Common visual aesthetic experience within the art therapy relationship deeply involves both patient with severe dementia and therapist due to an aesthetic countertransference to the work; therefore, such patients become able to express and communicate aesthetic pleasure resulting from the activity Byers [3]. By making artistic choices that fitted with the environment of the patients, the therapist also expected to reactivate their imaginary world. 
The present observed behaviour showed that it was sometimes not possible to dissociate the artistic aspects from the relational ones confirming the previous Byers's hypothesis that aesthetics can bring a point of resonance into the therapeutic relationship Byers [3]. Probably motivated by the established interpersonal trust, most of the patients verbally expressed their will to share their feelings of sympathy with the therapist. Interestingly, when in 1873 the German philosopher Robert Vischer introduced the term of empathy ("Einfühlung"), it was to express the "aesthetic sympathy" he felt when he was presented with art. It is very likely that the neurodegenerative disease reinforced the patients' dependency, but it was obvious that the patients liked to share what they aesthetically felt. Aesthetics is not only technical knowledge. Such intimacy is seen in the helping relationship, when the art therapist and the patient are engaged in a creative activity such as art therapy. Intimacy in a therapeutic context depends primarily on trust and may involve empathy and sympathy Kossak [94].

This intimacy is seen to make the link with the increase of positive feelings when a pleasant situation is shared, because the sharing amplifies the intensity of the experience Boothby et al. [95]. Modern art therapy encourages this sharing for educational purposes (assertiveness) and results have suggested that more and less trained therapists can be equally liked and trusted Horvath et al. [93]. In a study assessing strategies to raise self-esteem in female juvenile offenders, an art psychotherapy approach was seen to show a significant increase in personal connections (characterized, among other things, by trust) compared to a plastic art-based strategy that only addressed technical knowledge Hartz et al. [47]. The present study also focused the patient and therapist experiential collaboration on emotion-focused therapy, which offered a mutual involvement of equals and required the patient's agreement and commitment, and her coaching and even teaching Berdondini et al. [27]. Felt and expressed positive emotions engage in active imagination and healing Darewych et al. [2,96]. Similarly, the skill to build up a trusting and long-standing patient-physician relationship encouraged physicians to resonate with the patient emotionally Derksen et al. [69], even if more and more new forms of trust relations may be emerging in the context of health care delivery, reflecting a change in motivations for trust from affect-based to cognition-based trust Rowe \& Calnan [97]. Anyway, for patients affected by neurodegenerative disease, affect-based trust was preponderant. The determined impact of the centred-person approach was found to be significantly higher than the MMSE impact (Table 4).

\section{Risk Versus Trust}

Mutual trust implies a mutually perceived promotive interdependence, i.e., a cooperative expectation from the one who trusts and a cooperative intention from the trusted one; perceived trust can also increase with the communication level in the relationship Loomis [98]. Such, an open and non-judgmental collaboration, which enhances mutual trust, can involve the patient and the therapist encountering one another through taking risks
Berdondini et al. [27]. Berdondini referred to the notion of bond established by Bordin as part of the therapeutic alliance Bordin [62]. The very ideology of patient-centred therapy tends to mute the responsibilities of the therapist and highlight those of the patient Bordin [62]. In any case, the patient takes some risks of sharing her/his experience and in developing a collaborative experience. Risk is crucial to the operation of trust, which results from cooperative behaviour. To trust is to let another think about and take action to protect and advance something that the "truster" cares about Baier [99]. Deutsch also defined two processes through the development of trust for the trusting person Deutsch [100]: the formation of expectations and the translation of those expectations into behaviour under risk.

Similarly, Luhmann defined confidence as "an anticipation of the future based on prior experience and which aims to reduce the complexity of the future world" Luhmann [101]. Complexity therefore characterizes a potential for undetermined events and confidence aims to reduce uncertainty and consequently the feeling of risk. Luhmann precisely defined in German the word "vertrauen" to mirror English, which dissociates the notions of confidence and trust. He translated self-confidence as "insured confidence" and trust as "decided confidence" Luhmann [102]. Decided confidence presupposes a risky situation that one thinks to avoid by deciding to rely on others (developed trust, part 1 of the proposed model), whereas insured confidence corresponds to the feeling of assurance in a situation where one would not imagine that the events are otherwise as expected (developed self-confidence, part 2 of the model). Certainly, in an affective context of trust, severe neurodegenerative disease patients are able to decide to take risks. This behaviour was verbally expressed by some of the patients at the Dijon University Hospital as an actual fear: "What do you make me do?" They continued to do such tasks anyway.

\section{From Trust to Self-Confidence}

Carl Rogers's philosophy is based on a trust in an inherent impulse toward growth in every individual (Rogers, 2016). Proposed theories of trust concern the question of whether trust is a belief, an expectation, an attitude or an emotion; theoreticians have proposed cognitive, will-based or affective accounts of trust Baier et al. [99,25,103-105].Baier proposed a will-based account of trust involving the competences and the goodwill of the trustee Baier [99]. However, like Jones, the present results reinforce affective accounts of trust, depicting it as a behavior and emotion. It is likely that people diagnosed with severe-stage neurodegenerative diseases preferably rely on trust and self-confidence via their affect and later via their connotation in order to switch to the active mode. Self-confidence involves an affective attitude in addition to one's competence Jones [25]. For Jones there is a parallel between trust and self-confidence. She distinguishes "be self-confident" and "trust yourself" because of an important difference between the two: willingness. With self-confidence, people are only worried about their capacities rather than their will. On the other hand, 
will is part of trust and one needs to trust oneself - for instance, when one is worried about the possibility of self-sabotage Jones [25]. During the opening session, some patients already expressed their willingness to actively collaborate, meaning they were in the "trust yourself" concept but not yet in the "be self-confident" one. This way to encompass trust can be seen as an optimistic attitude to oneself. In the standard case, the confident expectation that the one trusted will respond directly and favourably to the thought that the "truster" is counting on them is itself grounded in the attitude of optimism. Trust is optimism about the goodwill and competence of another, the way optimism leads people to anticipate a favourable outcome. This attitude of optimism makes the difference between trust and reliance Jones [25]. Overall, women of the University Hospital of Dijon diagnosed with neurodegenerative diseases made an optimistic choice in according trust.

\section{Attachment}

Neurodegenerative disorders do not prevent the fundamental aspects of a personality to manifest. One case expressed this between-people variability by showing a patient regularly refusing to attend the sessions (e.g., entering the room) or remaining in a contemplative mode. There was an opportunity to meet the patient's daughter's and discuss her mother's relationships. She declared that she had never trusted people throughout her life, even her close family. She had always been a lonely woman, without any attachment. Since John Bowlby, the literature has described attachment theory and close relationships following two dimensions: attachment anxiety and attachment avoidance Bowlby [106]. As such, patient attachment is a mix between on one hand the fears of rejection and abandonment and on the other hand the fear of intimacy, of getting close to others Benett et al. [106-108]. The role of patient attachment shows that more securely attached persons are more likely to experience positive adjustment, and therefore their rehabilitation and control of their health-related quality of life is better Benett et al. [107]. It is likely that during this survey, the therapist faced the four attachment categorisations defined by Bartholomew et al. [109]: secure, preoccupied, fearful and dismissing. It is very likely that this patient belonged to an insecure attachment pattern, which can display a weaker working alliance compared to the secure ones Smith et al. [110]. On the other hand, patient attachment profiles do not independently relate to working alliances Bucci et al. [111]. Indeed, attachment styles can be modified through therapeutic relationships Bowlby $[106,110,112]$. An adapted behaviour can match insecure patients and modify their core attachment patterns. How many attended sessions would have been required in order for this patient to be shifted to the active mode? At least twenty, if we refer to Table 4.

\section{Strengths \& Limitations of the Study}

Regarding the methodology, the observed normal distribution of the data confirms that there was a sole field factor influencing the observations. With the additional and exponential influence of two or three field determinants, data sets would have led to a skewed distribution. It can be supposed that this unidimensional model is due to the way the therapist quoted the observations. This is likely why there is some consistency with previous observations collected by the same therapist but under different conditions (different geographical locations and time of the study, mild cognitive impairment with home-based people; Deygout [92]. This is also consistent with other studies in which the therapist's trust was regarded as unidimensional from the patients' perspectives and a unidimensional conceptual model was found more representative and confirmed by the fact that global items were preferred and account for the largest category Hall et al. [113-118]. Anyway, a further generalisation of the 36-item grid could be done via the establishment of its inter-rater reliability (Kappa coefficient of concordance), obtained, for instance, from two trained observers rating the same individuals Kinney et al. [22]. This would quantify the bias due to the subjective part of the therapist's quotation.

The main limitations of this observational case study are : 1) the limited size of the observed group (12 patients with 15\% of nonquoted items, which led to a significant and consistent remaining data set - 563 blanks out of 3852); 2) the absence of a control group of patients either without any neurodegenerative disease (MMSE of 37) or encountering a non-empathic approach; and 3) the quotations conducted by the therapist himself in charge of the sessions (methodological bias). Significant behavioural changes and notable trends in the direction of change were identified during the four-month sessions simultaneously by the therapist and by the care staff (mainly a decrease in anxiety and agitation, better social behaviours, positive emotions). Thus, the influence of the Rogers approach may be considered even more compelling in light of the limits inherent in this research. Another bias observed in this research design could have been the confounding effects of the selected patients' concurrent participation in other artistic interventions within their residential programme. However, during the four-month follow-up, only one person attended a choir once a week, which limited this bias.

\section{Implications for Art Therapy Practice}

This descriptive study aimed to increase knowledge of the influence of trust that Alzheimer's patients place in the practitioner in art therapy through the care process. As the result of the observed behavioural outcomes, trust can significantly contribute to facilitate the commitment in the activity and therefore the physical engagement in the art making. This is particularly noticeable at the beginning of the process at least during the first sessions when the built interpersonal trust strengthens the therapeutic relationship. For the art therapists working with Alzheimer's disease people, this study recommends first increasing the empathic approach of practitioners to help the patient to develop trust. It also suggests better efficiency in the healthcare process when using a person- 
centred approach such as that established by Carl Rogers. Empathy as well as absence of judgment facilitate aesthetic expression and creativity.

\section{Conclusion}

Severe-stage Alzheimer's patients require specific interpersonal styles when they face a practitioner in art therapy. A trust-based relationship established by the therapist can be a gateway to reactivate their self-confidence and provoke a physical engagement essential to the art-therapeutic activity, which ultimately will lead to a decrease in anxiety. Illustrated by the model proposed in the present study, Carl Rogers' person-centred approach appeared to be suitable for this purpose. In particular, empathy was regarded as essential to reinforce the patient's trust establishment in the therapeutic relationship. The Rogers approach, as well as his dynamics of change theory, can apply to severe-stage neurodegenerative disease people and the reactivation of patients' self-confidence. Such an approach is recommended at the beginning of the care process, and then must be released when the patients express assertiveness.

\section{Acknowledgement}

The authors acknowledge the care staff of the Dijon University Hospital for its welcome, its help and support in the realization of this study. The authors also acknowledge Mrs. Josiane Vergeot of the document communication department of the library of the Faculty of Medicine of Grenoble for her helpful support in advising the most appropriate literature.

\section{References}

1. Collie KR, Bottorff JL, Long BC (2006) A narrative view of art therapy and art making by women with breast cancer. J Health Psychol 11(5): 761-775.

2. Darewych OH, Bowers NR (2018) Positive arts interventions: creative clinical tools promoting psychological well-being. Int J Art Ther 23(2): 62-69.

3. Byers A (2011) Visual aesthetics in dementia. Int J Art Ther 16(2): 81-89.

4. Ehresman C (2014) From rendering to remembering: Art therapy for people with Alzheimer's disease. Int J Art Ther 19(1): 43-51.

5. Hannemann BT (2006) Creativity with dementia patients. Can creativity and art stimulate dementia patients positively? Gerontology 52(1): 5965.

6. Lack L (2004) Portals: Primary experience vs. translated experience: The implications for aesthetics healing and creativity in dance theater and movement dance therapy. The Journal of Pedagogy Pluralism and Practice 3(1).

7. Miller BL (2008) Creativity in the context of neurologic illness. CNS Spectr 13(2): 7-9.

8. Wood MJM, Low J, Molassiotis A, Tookman A (2013) Art therapy's contribution to the psychological care of adults with cancer: A survey of therapists and service users in the UK. Int J Art Ther 18(2): 42-53.

9. Forestier R (2009) [in French] Tout savoir sur l'Art-thérapie. ed. Favre Lausanne.

10. Lusebrink VB (2004) Art therapy and the brain: An attempt to understand the underlying processes of art expression in therapy. Journal of the American Art Therapy Association 21(3): 125-135.
11. Lefèvre C, Ledoux M, Filbet M (2015) Art therapy among palliative cancer patients: Aesthetic dimensions and impacts on symptoms. Palliative and Supportive Care 14(4): 376-380.

12. Eekelaar C (2011) Art gallery-based interventions in dementia care. D Clin Psych Thesis Christ Church University Canterbury.

13. Eekelaar C, Camic PM, Springham N (2012) Art galleries episodic memory and verbal fluency in dementia: an exploratory study. Psychol Aesthet Creat Arts 6(3): 262-272.

14.Graham DJ, Stockinger S, Leder H (2013) An island of stability: art images and natural scenes - but not natural faces - show consistent esthetic response in Alzheimer's-related dementia. Front Psychol 4: 107.

15. Halpern AR, Ly J, Elkin Frankston S, O Connor MG (2008) I know what I like: Stability of aesthetic preference in Alzheimer's patients. Brain and Cognition 66(1): 65-72.

16. Baker R, Bell S, Baker E, Gibson S, Holloway J, et al. (2001) A Randomized Controlled Trial of the Effects of Multi-Sensory Stimulation (MSS) for People with Dementia. British J Clin Psycho 40(1): 81-96.

17. Guétin S, Portet F, Picot MC, Pommié C, Messaoudi M, et al. (2009) Effect of music therapy on anxiety and depression in patients with Alzheimer's type dementia : randomised controlled study. Dement Geriatr Cogn Disord 28(1): 36-46.

18. Hattori H, Hattori C, Hokao C, Mizushima K, Mase T (2011) Controlled study on the cognitive and psychological effect of coloring and drawing in mild Alzheimer's disease patients. Geriatr Gerontol Int 11(4): 431437.

19. Mimica N, Kalinić D (2011) Art therapy may be beneficial for reducing stress - related behaviours in people with dementia - case report. Psychiatr Danub 23(1): 125-128.

20. Ozdemir L, Akdemir N (2009) Effects of multisensory stimulation on cognition depression and anxiety levels of mildly affected Alzheimer's patients. J Neurol Sci 283(1-2): 211-213.

21. Gross SM, Danilova D, Vandehey MA, Diekhoff GM (2015) Creativity and dementia: does artistic activity affect well-being beyond the art class? Dementia 14(1): 27-46.

22. Kinney JM, Rentz CA (2005) Observed well-being among individuals with dementia: Memories in the Making an art program versus other structured activity. American Journal of Alzheimer's Disease and Other Dementias 20(4): 220-227.

23. Rentz CA (2002) Memories in the Making ${ }^{\oplus}$ : Outcome-based evaluation of an art program for individuals with dementing illnesses. Am J Alzheimers Dis Other Demen 17: 175-181.

24. Rusted J, Sheppard L, Waller DE (2006) A Multi-centre Randomized Control Group Trial on the Use of Art Therapy for Older People with Dementia. Group Analysis 39(4): 517-536.

25. Sauer PE, Fopma Loy J, Kinney JM, Lokon E (2014) It makes me feel like myself: Person-centered versus traditional visual arts activities for people with dementia. Dementia 15(5): 895-912.

26. Baran Z, Cangöz B, Ozel Kizil ET (2014) The impact of aging and Alzheimer's disease on emotional enhancement of memory. Eur Neurol 72(1-2): 30-37.

27. Berdondini L, Elliott R, Shearer J (2012) Collaboration in experiential therapy. Journal of Clinical Psychology 68(2): 159-167.

28. Boller F, El Massioui F, Devouche E, Traykov L, Pomati S, et al. (2002) Processing emotional information in alzheimer's disease: Effects on memory performance and neurophysiological correlates dement. Geriatr Cogn Disord 14(2): 104-112.

29. Klein Koerkamp Y, Baciu M, Hot P (2012) Preserved and impaired emotional memory in Alzheimer's disease. Front Psychol 3: 331.

30. Mammarella N, Fairfield B (2014) Emotional working memory and Alzheimer's disease. International Journal of Alzheimer's Disease. 
31. Perrin M, Henaff MA, Padovan C, Faillenot I, Merville A, et al. (2012) Influence of emotional content and context on memory in mild Alzheimer's disease. J Alzheimers Dis 29(4): 817-826.

32. Camic PM, Baker EL, Tischler V (2016) Theorizing how art gallery interventions impact people with dementia and their caregivers. Gerontologist 56(6): 1033-1041.

33. Camic PM, Tischler V, Pearman CH (2014) Viewing and making art together: a multi-session art-gallery-based intervention for people with dementia and their carers. Aging Ment Health 18(2): 161-168.

34. Flatt JD, Liptak A, Oakley MA, Gogan J, Varner T, et al. (2015) Subjective experiences of an art museum engagement activity for persons with early-stage Alzheimer's disease and their family caregivers. Am J Alzheimers Dis Other Demen 30(4): 380-389.

35. Hazzan AA, Humphrey J, Kilgour Walsh L, Moros KL, Murray C, et al. (2016) Impact of the 'Artful Moments' intervention on persons with dementia and their care partners: a pilot study. Can Geriatr J 19(2): 1-8.

36. Selberg S (2015) Modern Art as public care: Alzheimer's and the aesthetics of universal personhood. Med Anthropol Q 29(4): 473-491.

37. Cowl AL, Gaugler JE (2014) Efficacy of creative arts therapy in treatment of Alzheimer's disease and dementia: A systematic literature review. Activities Adaptation \& Aging 38(4): 281-330.

38. Olazaran J, Reisberg B, Clare L, Cruz I, Peña Casanova J, et al. (2010) Nonpharmacological therapies in Alzheimer's disease: a systematic review of efficacy. Dement Geriatr Cogn Disord 30(2): 161-178.

39. Finnema E, Dröes RM, Ettema T, Ooms M, Adèr H, et al. (2005) The effect of integrated emotion-oriented care versus usual care on elderly persons with dementia in the nursing home and on nursing assistants: a randomized clinical trial. Int J Geriatr Psychiatry 20(4): 330-343.

40. Kalenzaga S, Bugaïska A, Clarys D (2013) Self-reference effect and autonoetic consciousness in Alzheimer disease: evidence for a persistent affective self in dementia patients; Alzheimer Dis. Assoc. Disord 27(2): 116-122.

41. Fredrickson BL (1998) What good are positive emotions? Rev Gen Psycho 2: 300-319.

42. Herholz SC, Herholz RS, Herholz K (2013) Non-pharmacological interventions and neuroplasticity in early stage Alzheimer's disease. Expert Rev Neurother 13(11): 1235-1245.

43. Mirabella G (2015) Is art therapy a reliable tool for rehabilitating people suffering from brain/mental diseases? J Altern Complement Med 21(4): 196-199.

44. Chancellor B, Duncan A, Chatterjee A (2014) Art therapy for Alzheimer's disease and other dementias. J Alzheimers Dis 39(1): 1-11.

45. Chen CCC (2015) Exploring and discovering the self art therapy-based activity. Review of Arts and Humanities 4(1): 50-59.

46. Franklin M (1992) Art therapy and self-esteem. Journal of the American Art Therapy Association 9(2): 78-84

47. Hartz L, Thick L (2005) Art therapy strategies to raise self-esteem in female juvenile offenders: a comparison of art psychotherapy and art as therapy approaches. Journal of the American Art Therapy Association 22(2): 70-80

48. Lambert MJ (1989) The individual therapist's contribution to psychotherapy process and outcome. Clinical Psychology Review 9(4): 469-485.

49. Lambert MJ, OkiishiJC(1997) The effects of the individual psychotherapist and implications for future research; Clinical Psychology: Science and Practice 4(1): 66-75.

50. Lecomte C, Lecomte T (1999) Au-delà et en deçà des techniques cognitives béhaviorales dans le traitement des troubles graves : les facteurs communs. Santé mentale au Québec 24(1): 19-38.

51. Weinberger J (1995) Common factors aren't so common: the common factors dilemma. Clinical Psychology: Science and Practice 2(1): 45-69.
52. Uttley L, Scope A, Stevenson M, Rawdin A, Taylor Buck E, et al. (2015) Systematic review and economic modelling of the clinical effectiveness and cost-effectiveness of art therapy among people with non-psychotic mental health disorders. Health Technol Assess 19(18): 1-120.

53. Cavazos K (2012) Therapists' perspective on the effectiveness of art therapy. Master of social work, California State University, Sacramento.

54. Del Re AC, Flückiger C, Horvath AO, Symonds D, Wampold BE (2012) Therapist effects in the therapeutic alliance-outcome relationship: a restricted-maximum likelihood meta-analysis. Clin Psychol Rev 32(7): 642-649.

55. Lambert MJ, Barley DE (2001) Research summary on the therapeutic relationship and psychotherapy outcome. Psychotherapy: Theory Research Practice Training 38(4): 357-361.

56. Ackerman SJ, Hilsenroth MJ (2003) A review of therapist characteristics and techniques positively impacting the therapeutic alliance. Clinical Psychology Review 23(1): 1-33.

57. Fuertes JN, Toporovsky A, Reyes M, Osborne JB (2017) The physicianpatient working alliance: Theory research and future possibilities. Patient Educ Couns 100(4): 610-615.

58. Hardy GE, Cahill J, Barkham M (2007) Active ingredients of the therapeutic relationship that promote client change: a research perspective. In Gilbert P, Leahy R (Eds.). The therapeutic relationship in the cognitive behavioural psychotherapies. London: Routledge p. 24-42.

59. Huff NG, Nadig N, Ford DW, Cox CE (2015) Therapeutic alliance between the caregivers of critical illness survivors and intensive care unit clinicians. Ann Am Thorac Soc 12(11): 1646-1653.

60. Poremski D, Whitley R, Latimer E (2016) Building trust with people receiving supported employment and housing first services. Psychiatr Rehabil J 39(1): 20-26.

61. Berrios Rivera JP, Street RL, Garcia Popa Lisseanu MG, Kallen MA, Richardson MN, et al. (2006) Trust in physicians and elements of the medical interaction in patients with rheumatoid arthritis and systemic lupus erythematosus. Arthritis Rheum 55(3): 385-393.

62. Bordin ES (1979) The generalizability of the psychoanalytic concept of working alliance. Psychotherapy: Theory Research and Practice 16(3): 252-260.

63. Dupuis S, Mc Ainey CA, Fortune D, Ploeg J, Witt L (2016) Theoretical foundations guiding culture change: The work of the partnerships in dementia care alliance. Dementia 15(1): 85-105.

64. Poncet Jeanne M (2007) L'expressivité non verbale des personnes âgées atteintes de démence de type Alzheimer marqueur de leur affectivité préservée. Thèse de doctorat de psychologie Université Lumière Lyon 2 ; Ecole Doctorale Humanités et Sciences Humaines - Institut de Psychologie - Laboratoire de recherche Santé/Individu/Société EA 4129 ; Lyon.

65. Collie K (2003) A narrative view of visual creative expression as psychosocial support for women with breast cancer (thesis). The University of British Columbia Vancouver BC.

66. Franklin M (1990) The esthetic attitude and empathy: A point of convergence. American Journal of Art Therapy 29(2): 42.

67. Bachelor A (1988) How clients perceive therapist empathy: a content analysis of received empathy. Psychotherapy Theory Research \& Practice 25(2): 227-240.

68. Del Canale S, Louis DZ, Maio V, Wang X, Rossi G, et al. (2012) The relationship between physician empathy and disease complications: an empirical study of primary care physicians and their diabetic patients in Parma Italy. Acad Med 87(9): 1243-1249.

69. Derksen F, Bensing J, Lagro Janssen A (2013) Effectiveness of empathy in general practice: a systematic review. Br J Gen Pract 63(606): 76-84.

70. Hojat M, Louis DZ, Markham FW, Wender R, Rabinowitz C, et al. (2011) Physicians' empathy and clinical outcomes for diabetic patients. Acad Med 86(3): 359-364. 
71. Lee King PA, Cederbaum JA, Kurzban S, Norton T, Palmer SC, et al. (2015) Role of patient treatment beliefs and provider characteristics in establishing patient-provider relationships. Fam Pract 32(2): 224-231.

72. Raglio A, Bellelli G, Traficante D, Gianotti M, Ubezio MC, et al. (2008) Efficacy of music therapy in the treatment of behavioral and psychiatric symptoms of dementia. Alzheimer Dis Assoc Disord 22(2): 158-162.

73. Evans Jones C, Peters E, Barker C (2009) The therapeutic relationship in CBT for psychosis: client therapist and therapy factors. Behav Cogn Psychother 37(5): 527-540.

74. Rogers C (1961) On becoming a person: A therapist's view of psychotherapy. Houghton-Mifflin Boston.

75. Malchiodi CA (2003) Handbook of art therapy; chapter six: humanistic Approaches. The Guilford Press.

76. Clissett P, Porock D, Harwood RH, Gladman JR (2013) The challenges of achieving person-centred care in acute hospitals: a qualitative study of people with dementia and their families. Int J Nurs Stud 50(11): 14951503.

77. Kelly F (2010) Recognising and supporting self in dementia: A new way to facilitate a person-centred approach to dementia care. Ageing \& Society 30: 103-124.

78. Livingston G, Kelly L, Lewis Holmes E, Baio G, Morris S, et al. (2014) Nonpharmacological interventions for agitation in dementia: systematic review of randomised controlled trials. The British Journal of Psychiatry 205(6): 436-442

79. Wong KM, Cloninger CR (2010) A person-centered approach to clinical practice; focus. Am Psychiatr Publ 8(2): 199-215.

80. Bernhard H, Millot C (2007) [in French] L’apport spécifique de l'autoévaluation par le cube harmonique dans la restauration de l'estime de soi in L'évaluation en art-thérapie pratiques internationales. ed. Elsevier-Masson Paris p. 73-80.

81. Rogers C (1951) Client-Centered Therapy. The Riverside Press. Cambridge Massachusetts.

82. Folstein MF, Folstein SE, McHugh PR (1975) Mini-mental state; A practical method for grading the cognitive state of patients for the clinician. Journal of Psychiatric Research 12(3): 189-198.

83. Turnbull J, O’May F (2002) GPS and clients views of art therapy in an Edinburgh practice. International Journal of Art Therapy Inscape 7: 2629

84. Wijk H, Berg S, Sivik L, Steen B (1999) Colour discrimination colour naming and colour preferences among individuals with Alzheimer's disease. Int J Geriatr Psychiatry 14(12): 1000-1005.

85. Morstyn R (2010) How the philosophy of Merleau-Ponty can help us understand the gulf between clinical experience and the doctrine of evidence-based psychotherapy. Australasian Psychiatry 18(3): 221-225.

86. Lawton MP (1994) Quality of life in Alzheimer disease. Alzheimer Dis Assoc Disord 8(3): 138-150.

87. Lawton MP (1997) Assessing quality of life in Alzheimer's disease research; Alzheimer Dis Assoc Disord 11(6): 91-99.

88. Bickmore TW, Mitchell S, Jack B, Paasche Orlow M (2010) Response to a relational agent by hospital patients with depressive symptoms. Interact Comput 22(4): 289-298.

89. Peschken WE, Johnson ME (1997) Therapist and client trust in the therapeutic relationship. Psychotherapy Research 7: 439-447.

90. Quattrini GP (2013) [in Italian] Il problema dell'alleanza nella relazione terapeutica; Istituto Gestalt Firenze. Psicoterapia Counselling Fenomenologia Informazione $\mathrm{n}^{\circ} 22$.

91. Swinth RL (1967) The Establishment of a Trust Relationship; Journal of Conflict Resolution 11: 335-344.

92. Deygout F (2015) [in French] Recognize an existence through artistic activities predominantly music and visual arts for people with
Alzheimer-type neurodegenerative diseases. Gradation thesis for the title of art therapist AFRATAPEM Tours France.

93. Horvath AO, Luborsky L (1993) The role of the therapeutic alliance in psychotherapy. Journal of Consulting and Clinical Psychology 61: 561573.

94. Kossak MS (2009) Therapeutic attunement: A transpersonal view of expressive arts therapy. The Arts in Psychotherapy 36(1): 13-18.

95. Boothby EJ, Clark MS, Bargh JA (2014) Shared experiences are amplified. Psychol Sci 25(12): 2209-2216.

96. Rogers N (2016) Person-centred expressive arts therapy: A path to wholeness. In Rubin JA (Eds.). Approaches to art therapy: Theory and technique ( $3^{\text {rd }}$ Edn.). Routledge, New York NY, USA, pp. 230-248.

97. Rowe R, Calnan M (2006) Trust relations in health care: developing a theoretical framework for the 'new' NHS. J Health Organ Manag 20(5): 376-396.

98. Loomis J (1959) Communication the development of trust and cooperative behaviour. human relations 12: 305-315

99. Baier A (1991) Trust the tanner lectures on human values. Princeton University Princeton NJ.

100. Deutsch M (1973) The resolution of conflict: Constructive and destructive processes. Yale University Press.

101. Luhmann N (1968) Vertrauen - Ein mechanismus der reduktion sozialer komplexität. ed. UTB Stuttgart.

102. Luhmann N (1979) Trust and power: two works; translated by Howard Davis John Raffan and Kathryn Rooney (Eds.). Wiley New York, USA.

103. Hupcey JE, Penrod J, Morse JM, Mitcham C (2001) An exploration and advancement of the concept of trust J Adv Nurs 36(2): 282-293.

104. Jones K (1996) Trust as an affective attitude. Ethics 107(1): 4-25.

105. Simon J (2013) Trust In: Pritchard D (Ed.) Oxford Bibliographies in Philosophy Oxford University Press New York, USA.

106. Bowlby J (2008) A secure base: Parent-child attachments and healthy human development ed. Basic Books New York, USA.

107. Benett JK, Fuertes JN, Keitel M, Phillips R (2011) The role of patient attachment and working alliance on patient adherence satisfaction and health-related quality of life in lupus treatment. Patient Educ Couns. 85(1): 53-59.

108. Brennan KA, Clark CL, Shaver PR (1998) Self-report measurement of attachment: an integrative overview. In Simpson, Rholes (Eds.). Attachment theory and close relationships. Guilford Press New York, USA, p. 46-76.

109. Bartholomew K, Horowitz LM (1991) Attachment styles among young adults: a test of a four-category model. Journal of Personality and Social Psychology 61(2): 226-244.

110. Smith AE, Msetfi RM, Golding L (2010) Client self-rated adult attachment patterns and the therapeutic alliance: a systematic review. Clinical Psychology Review 30(3): 326-337.

111. Bucci S, Seymour Hyde A, Harris A, Berry K (2015) Client and therapist attachment styles and working alliance. Clin Psychol Psychother 23(2): 155-165.

112. Wongpakaran T, Wongpakaran N (2012) How the interpersonal and attachment styles of therapists impact upon the therapeutic alliance and therapeutic outcomes. J Med Assoc Thai 95(12): 1583-1592.

113. Hall MA, Zheng B, Dugan E, Camacho F, Kidd KE, et al. (2002) Measuring patients' trust in their primary care providers. Medical Care Research \& Review 59(3): 293-318.

114. Gilbert P (2007) Evolved minds and compassion in the therapeutic relationship. In Gilbert P, Leahy R (Eds.) The Therapeutic Relationship in the Cognitive Behavioural Psychotherapies. London: Routledge pp. 106-143. 
115. Govier T (1993) Self-trust autonomy and self-esteem. Hypatia 8(1): 99-120.

116. Pache M, Smeets CH, Gasio PF, Savaskan E, Flammer J, et al. (2003) Colour vision deficiencies in Alzheimer's disease. Age Ageing 32: 422 426.

\section{ISSN: 2574-1241}

DOI: 10.26717/BJSTR.2019.22.003727

François Deygout. Biomed J Sci \& Tech Res

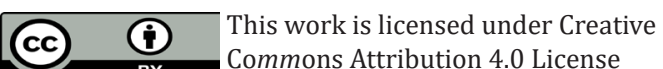

Submission Link: https://biomedres.us/submit-manuscript.php
117. Reynolds F (2009) Colour and communion: Exploring the influences of visual art making as a leisure activity on older women's subjective well-being. J Aging Studies 24: 135-143.

118. Vischer R (1873) [in German] Über das optische formgefühl: ein beitrag zur aesthetik (On the optical sense of form: a contribution to aesthetics). ed. Hermann Credner Leipzig.

$\begin{array}{ll}\text { BIOMEDICAL } & \text { Assets of Publishing with us } \\ \text { RESEARCHES } & \text { - Global archiving of articles } \\ \text { - Immediate, unrestricted online access } & \text { - Rigorous Peer Review Process } \\ & \text { - Authors Retain Copyrights }\end{array}$

